\title{
Concepções sobre Psicologia Organizacional e do Trabalho entre estudantes de Psicologia
}

\section{Conceptions on Organizational and Work Psychology among students of Psychology}

\author{
Mário Lázaro Camargo ${ }^{1}$, Renata Carvalho de Jesus Macedo ${ }^{2}$
}

\begin{abstract}
Resumo
Esta pesquisa investigou as concepções sobre Psicologia Organizacional e do Trabalho (POT) entre estudantes de Psicologia do interior paulista. Foi realizada a comparação entre respostas de estudantes iniciantes e concluintes $(n=99)$. Os dados foram coletados por meio de questionário individual, aplicado em cinco unidades de ensino mediante prévia autorização institucional e dos participantes. Devidamente tratados, os dados foram submetidos à análise de conteúdo. A hipótese que motivou esta pesquisa foi de que haveria diferença qualitativa entre respostas emitidas por estudantes iniciantes e concluintes, e que tal diferença seria decorrente da exposição dos mesmos aos conteúdos proporcionados pelo curso. Os resultados, contudo, não confirmaram essa hipótese. Eles refletem uma realidade de concepções sobre a POT que inspira cuidados e a organização de um conjunto de práticas, em nível interinstitucional, para promover melhorias. Assim, são propostas estratégias com a finalidade de contribuir para um melhor ensino da POT.
\end{abstract}

Palavras-chave: Formação profissional. Psicologia Organizacional e do Trabalho. Concepções.

\begin{abstract}
This research investigated conceptions about Organizational Psychology and Work in Psychology students from the interior of São Paulo State. Comparison was made between responses of beginning and ending students $(\mathrm{n}=99)$. Data were collected by means of an individual questionnaire, applied in five teaching units with previous authorization of institutions and participants. Duly treated, data were submitted to a content analysis. Hypothesis that motivated this research was that there would be a qualitative difference between answers issued by beginning and ending students, and such difference would be due to their exposure to the contents provided by the course. Results, however, did not confirm this hypothesis. They reflect a reality of conceptions about Organizational Psychology and Work that inspire both care and a set of teaching practices at the inter-institutional level to promote improvements. Thus, strategies are proposed to contributing to a better teaching of Organizational Psychology and Work.
\end{abstract}

Keywords: Professional qualification. Organizational and Work Psychology. Conceptions.

\footnotetext{
${ }^{1}$ Doutorado em Psicologia pela Universidade de São Paulo - Faculdade de Filosofia, Ciências e Letras de Ribeirão Preto (USP-FFCLRP), Ribeirão Preto, São Paulo, Brasil. Professor da Universidade Estadual Paulista Júlio de Mesquita Filho (Unesp), São Paulo, Brasil. E-mail: mario.camargo@fc.unesp.br

${ }^{2}$ Mestrado pelo Programa de Pós-graduação em Psicologia do Desenvolvimento e Aprendizagem da Universidade Estadual Paulista Júlio de Mesquita Filho (Unesp-Bauru), Bauru, São Paulo, Brasil.
} 
A Psicologia Organizacional e do Trabalho (POT), elege como seu objeto de estudo e intervenção a relação que se estabelece entre o ser humano, seu trabalho e a organização na qual estes se encontram coexistindo. Sua missão implica em analisar e compreender como interagem as várias dimensões que constituem a dinâmica e a vida das pessoas, grupos e organizações de trabalho, com o objetivo de desenvolver estratégias que visam a promoção da saúde, a prevenção da doença, a qualidade de vida dos trabalhadores (ZANELLI; BASTOS; RODRIGUES, 2014).

Embora possamos afirmar que a identidade e o conjunto das práticas profissionais do Psicólogo Organizacional e do Trabalho estejam bem definidas para os mesmos, para o Conselho Federal de Psicologia (CFP) e para a Associação Brasileira de Psicologia Organizacional e do Trabalho (SBPOT), não podemos dizer o mesmo em relação a como este profissional e sua área de especialidade são vistos pela sociedade e por gestores de grande parte das organizações de trabalho brasileiras. Muito provavelmente, o que ainda se tem de confusão acerca da identidade e, portanto, acerca do papel e fazeres deste Psicólogo, deve-se ao processo histórico de desenvolvimento da área que provém das práticas de Administração de Recursos Humanos $(\mathrm{ARH})$ e das primeiras iniciativas de utilização dos conhecimentos e técnicas produzidos pela Psicologia nas indústrias, principalmente no período da Revolução Industrial, quando então a Psicologia era fortemente requisitada para desenvolver atividades relacionadas à seleção de pessoas ou no aprimoramento das potencialidades humanas aplicáveis ao trabalho, via treinamentos, objetivando o aumento da produtividade individual e coletiva. Nas palavras de Zanelli, Bastos e Rodrigues (2014, p. 559):

[...] o movimento de crítica ampla ao modelo de atuação profissional do psicólogo no Brasil, intenso nos anos 1970 e 1980 , coincidente com um período acirrado e com o término do regime militar, teve importantes reflexos na área de POT. O psicólogo organizacional (ainda atuando nos moldes do psicólogo industrial) foi um dos alvos mais criticados, senão o modelo mais criticado de atuação profissional da psicologia, sob o estigma de descomprometimento com as demandas sociais.

A Psicologia inserida no contexto das organizações de trabalho não demorou a ser chamada de Psicologia da Indústria - e posteriormente, Psicologia Organizacional - e a se identificar com as demandas advindas das organizações por produtividade, desenvolvimento, competitividade, concorrência por fatias cada vez maiores do mercado, sendo este sempre dirigido pelas perspectivas de um capitalismo em franco processo de desenvolvimento. E vale pontuar: entenda-se por esta identificação um comprometimento nítido e polarizado, ou seja, a Psicologia da Indústria e seus profissionais, de fato serviam mais aos interesses das organizações do que dos trabalhadores (ZANELLI, 2002), diferentemente do que hoje propõe a POT que, não obstante a sua preocupação com o desenvolvimento das organizações, lida com a complexa tarefa de promover e garantir a qualidade de vida no trabalho e a saúde do trabalhador.

As práticas de administração dos chamados recursos humanos passaram a receber, assim, e naquele período dito gestacional ou fundacional, as contribuições da Psicologia, da Sociologia, da Administração de Empresas, da Economia e, num crescente processo de sistematização, com inclusive, significativo rigor científico, constituiuse sob a forma de subsistemas (MARRAS, 2016). Autores como Chiavenato (2009), Ivancevich (2008) e Spector (2012) conceituam a ARH como tendo seu desenvolvimento de maneira situacional ou contingencial, agindo de acordo com a cultura organizacional do ambiente, dependendo de variáveis muito específicas. Para Chiavenato (2009), a ARH, modernamente chamada Gestão de Pessoas (GP), assim pode ser estruturada: envolvem os processos de provisão (recrutamento e seleção de pessoas), aplicação (o que tange a descrição e análise de cargos, integração de novos indivíduos ao contexto de trabalho e 
organizacional), manutenção (benefícios que podem manter o trabalhador ali, como convênios, higiene e segurança no trabalho, serviços sociais, entre outros), desenvolvimento (treinamento e capacitação do trabalhador visando seu amplo desempenho e produtividade) e monitoração (sistemas de controle sobre o trabalhador: frequência, produção, comprometimento, desempenho). Todas essas pequenas áreas ou práticas formam os subsistemas de funcionamento da grande área intitulada ARH/GP e possuem uma dinâmica integrada e interdependente, ou seja, um subsistema não funciona da mesma forma na ausência do outro e sofre influências positivas ou negativas relativas à situação de funcionamento dos demais subsistemas.

Para concluir a apresentação desta área constitutiva da estrutura das organizações de trabalho, em especial aquelas de médio e grande porte cuja gestão se encontra já mais profissionalizada, e fortalecendo a conexão com o foco de nossa pesquisa, faz-se necessário pontuar que, historicamente no Brasil, este tem sido um espaço de forte presença e atuação dos Psicólogos (ZANELLI, 2002; ZANELLI; BASTOS; RODRIGUES, 2014). Contudo, a ARH/GP não é uma área de atuação exclusiva do Psicólogo, nem tampouco é domínio exclusivo, ou pretende ser, da POT. Esta é sim, uma área de atuação multiprofissional e interdisciplinar (ZANELLI, 2002). Doravante, postulamos que a presença do Psicólogo Organizacional e do Trabalho na ARH/ GP deve ser significativa, no sentido que o mesmo é um espaço privilegiado para sua atuação, uma vez que permite o mais franco contato com o objeto de estudo e intervenção da POT, a relação homem-trabalho-organização. Mas postulamos igualmente que a presença do Psicólogo na ARH/GP deve promover em sua dinâmica uma mudança significativa, marcada por uma atuação diferenciada e com foco na promoção da qualidade de vida no trabalho e da saúde do trabalhador, contribuindo assim para a desconstrução do paradigma ainda vigente, a saber: de uma atuação que, por conta de sua história ou tradição, ou por conta de uma vulnerabilidade, resultante das interferências e forças do contexto (histórico, social, econômico e cultural), em se tratando de exercício profissional ou de posicionamento político e ético, não cumpriu seu papel de transformação, vindo a representar, portanto, mais um complexo dispositivo de manutenção ou reprodução do status quo, no sentido de permitir a sobreposição dos direitos e interesses das organizações sobre os direitos e interesses dos trabalhadores.

Essa demanda por reflexões sobre a prática e pela busca de alternativas para o exercício profissionalnocontextodaPOT, econsequentemente a formação deste profissional, é que nos motivou ao desenvolvimento da presente pesquisa, posto que temos observado que muitas são as situações de falha/equívoco no processo discursivo e prático em relação a estes dois pontos fundamentais, a saber: 1) a variabilidade na conceituação de POT (por vezes incompleta, equivocada e ultrapassada) e dos fazeres deste Psicólogo ocorrida durante o processo de formação dos futuros profissionais; 2) a prática dos profissionais atuantes na área da POT (principalmente na ARH/GP e nas consultorias), que muitas vezes fazem corroborar as críticas recebidas histórica e hodiernamente. $\mathrm{O}$ fato é que o mercado de trabalho brasileiro ainda não reconhece de forma clara a identidade da POT e os fazeres do Psicólogo com ela identificado, e, por isso, confunde, ora por desconhecimento ora de maneira intencional, esta especialidade científica e profissional com denominações e práticas identificadas como a de "Analistas de Recursos Humanos", "Administradores de Departamento de Pessoal" ou ainda com o que faziam os próprios Psicólogos quando o que se tinha era uma Psicologia da Indústria, esta, obviamente, já ultrapassada teórica, metodológica e identitariamente.

Lidamos, pois, com a seguinte hipótese: eventuais falhas no processo formativo de Psicólogos, onde o contato com a POT se dá por meio de disciplinas, pesquisas e estágios, colaboram para uma manutenção de conceitos e, consequentemente, de práticas profissionais 
ainda distantes do que preconizam os autores mais atuais da POT, o Conselho Federal de Psicologia (CFP) e a Associação Brasileira de Psicologia Organizacional e do Trabalho (SBPOT).

Assim, buscamos investigar as concepções sobre a POT entre estudantes de Psicologia, em diferentes momentos de sua formação, ou seja, do primeiro ao terceiro anos do curso (INICIANTES), quando ainda não haviam passado pelas disciplinas (Psicologia Organizacional, Psicologia do Trabalho, Psicologia Organizacional e do Trabalho ou denominações afins) e dos quarto e quinto anos do curso (CONCLUINTES), quando já haviam cursado tais disciplinas e, em alguns casos, encontravam-se realizando estágios profissionalizantes na área, objetivando identificar relações entre essas concepções, o processo de formação em andamento e as formas de atuação do Psicólogo Organizacional e do Trabalho que vão se constituindo como certas ou adequadas para estes futuros profissionais.

\section{Método}

Esta é uma pesquisa de campo, seguindo os pressupostos da abordagem quanti-qualitativa em ciências humanas (GONZÁLES REY, 2005; MINAYO, 2016).

Nossa amostra foi composta por 99 estudantes de Psicologia, sendo 61 (62\%) deles iniciantes e 38 (38\%) concluintes. Os participantes da pesquisa obedeceram como critério de inclusão/ exclusão à mesma, o fato de estarem matriculados e frequentando um dos cinco cursos existentes na cidade onde a pesquisa aconteceu, sendo estes geridos por uma instituição pública estadual e por quatro instituições privadas.

A coleta de dados foi realizada por meio de preenchimento individual de questionário semiaberto (com questões a serem respondidas por meio de múltipla escolha e também abertas), onde constaram perguntas sobre o ano/termo/semestre do curso de Psicologia em que o participante se encontrava, as denominações das disciplinas que relacionam Psicologia e Trabalho que cursaram, para além de solicitar a construção de uma síntese conceitual sobre POT e dos fazeres do Psicólogo que atua nessa área.

A análise dos resultados deu-se por meio da técnicaintitulada “Análise deConteúdo"(BARDIN, 2011; CÂMARA, 2013), que objetiva dar um tratamento ao conteúdo encontrado, reunindo-o em categorias e permitindo uma visão estruturada do conteúdo narrado pelos participantes.

Considerando tal metodologia de pesquisa e as diretrizes presentes na Resolução 466/12, do Conselho Nacional de Saúde (BRASIL, 2012), entendemos que este projeto se inscrevia como obrigado aos trâmites relativos à pesquisa que envolve seres humanos, sendo o mesmo, portanto, submetido e aprovado por um Comitê de Ética em Pesquisa. Vale pontuar que, conforme constou no Termo de Consentimento Livre e Esclarecido, antecipadamente entregue, explicado e assinado pelos participantes da pesquisa, foi respeitado o sigilo em relação à identificação pessoal e institucional.

\section{Resultados e Discussões}

As cinco primeiras questões do instrumento visavam obter dados sociodemográficos dos participantes. A seguir, havia uma questão sobre o momento do curso (ano) em que o participante estava frequentando e, a última questão deste primeiro bloco versava sobre o período em que o participante estudava (se integral, noturno, vespertino etc.). Tais questões forneceram os resultados a seguir.

Entre os participantes, 78 eram mulheres e 21, homens. O participante mais jovem tinha 18 anos e o mais velho, 67. A idade média dos participantes foi, portanto, de 26 anos. A maioria dos participantes (90) fazia o curso no período noturno. Sete participantes estudavam em período integral e dois não responderam à questão. Os participantes estavam distribuídos, em relação ao momento (ano) no curso, da seguinte forma: 15 no primeiro ano; 36 no segundo ano; 11, no terceiro; seis no quarto; 28 no quinto e três no sexto, apesar 
de os cursos pesquisados terem todos a duração regular de cinco anos. Com relação à atividade remunerada, 51 participantes não trabalhavam; 25 estavam empregados; 19 faziam estágios; três trabalhavam como autônomos e um não respondeu.

A maior parte dos participantes do sexo masculino (14) está entre os iniciantes, os demais (sete) são do grupo dos concluintes. São 47 participantes do sexo feminino no grupo dos iniciantes e 31 no dos concluintes. Apenas um participante concluinte estuda em período integral; os demais (37) estudam no período noturno; seis participantes iniciantes estudam em período integral e 53, no período noturno.

Dentre os participantes da pesquisa, 37 iniciantes e 14 concluintes não trabalhavam. Apenas um dos iniciantes fazia estágio, enquanto 18 entre os concluintes o fazia. Trabalhavam como empregados 20 dos iniciantes e cinco dos concluintes; dois iniciantes e um concluinte trabalhavam de forma autônoma.

Os dados acima apresentados nos remetem a uma necessária atenção em relação a:

1. Prevalência quantitativa de mulheres (78,78\%) estudando Psicologia em relação a homens $(21,22 \%)$. Os resultados desta pesquisa, realizada numa cidade do interior paulista, corroboram os dados obtidos em âmbito nacional de que a Psicologia é uma ciência e profissão de marcante presença feminina. A pesquisa feita por meio de uma amostra probabilística no Cadastro Nacional de Psicólogos do CFP (CONSELHO FEDERAL DE PSICOLOGIA, 2013b) apontou para o fato de que as mulheres constituíam $89 \%$ da categoria. Comparada a outras pesquisas, também realizadas pelo CFP, verifica-se uma constante de resultados no sentido da predominância de mulheres sobre homens no exercício profissional da Psicologia, embora com uma pequena variação de percentual: na pesquisa realizada em 1988, o percentual de Psicólogas era de 87\% (CONSELHO FEDERAL DE PSICOLOGIA, 1988); já na pesquisa realizada em 2004, este percentual era de 91\% (INSTITUTO BRASILEIRO DE OPINIÃO PÚBLICA E ESTATÍSTICA, 2004). O Cadastro Nacional de Psicólogos, mantido pelo CFP, em consulta realizada recentemente nos apresenta os seguintes dados: o Estado de São Paulo possui um total de 89.482 profissionais cadastrados, dentre os quais 78.039 (87,21\%) são mulheres, 11.121 $(12,42 \%)$ são homens (CONSELHO FEDERAL DE PSICOLOGIA, 2017). A amostra de nossa pesquisa $(n=99)$ ainda se encontra em processo de formação, mas podemos afirmar que, com base nestes dados dos estudantes e, a exemplo do retrato nacional, teremos atuando no mercado de trabalho um contingente de Psicólogas em média três vezes superior ao de Psicólogos;

2. A maioria dos participantes da pesquisa estudava em período noturno (90\%). Dos cinco cursos de Psicologia em funcionamento na cidade pesquisada, quatro são oferecidos por instituições de caráter privado e apenas um por instituição de ensino público gratuito. Sendo assim, aqueles estudantes de Psicologia que não gozavam do benefício de bolsas de estudo ou da condição de ter os custos de sua inserção acadêmica pagos pela família, precisavam trabalhar para poder se manter estudando, o que justifica a maioria dos estudantes terem se vinculado a cursos de período noturno, período mais compatível com a possibilidade do exercício profissional que normalmente se dá em horário comercial. Estes nossos achados também são corroborados pelo levantamento realizado por Yamamoto, Falcão e Seixas (2011) que, dentre outros fatores pesquisados, também recorreram à situação sócio-econômica- 
familiar dos estudantes de Psicologia participantes do ENADE-2016 para definir seu perfil, concluindo que: do total de 23.613 respondentes das questões sociodemográficas do exame, $83,7 \%$ estudavam em instituições de caráter privado e $16,3 \%$ em instituições públicas, e que $50,1 \%$ estudavam em período noturno;

3. Do ponto de vista da relação com o trabalho, ou da aquisição de experiências profissionais, temos o seguinte quadro: $51(51,51 \%)$ dos participantes de nossa pesquisa afirmaram não exercer atividade profissional concomitante à atividade acadêmica na época em que se deu a coleta de dados; 19 (19,19\%) afirmaram fazer estágios; três $(3,03 \%)$ afirmaram trabalhar como profissionais autônomos e apenas $25 \quad(25,25 \%)$ relataram trabalhar na condição de empregados. Em síntese, temos que: seguramente $47,47 \%$ dos participantes já traziam consigo alguma experiência profissional, enquanto que para os demais $51,51 \%$, tal experiência não pode aqui ser afirmada como existente, posto que não sabemos se nunca trabalharam ou se apenas se encontravam fora do mercado de trabalho no momento da aplicação da pesquisa. Considerando a afinidade temática, duas questões respondidas por nossos sujeitos tiveram suas respostas analisadas conjuntamente, as questões 6 e 7, respectivamente: "No Brasil, em que áreas/especialidades você sabe ou já ouviu falar que o Psicólogo pode atuar?" e "Seu Curso de Formação do Psicólogo oferece disciplinas em quais destas áreas de atuação?”. Para a organização das respostas dos participantes, foi utilizada a proposta de categorização das especialidades em Psicologia do Conselho Federal de Psicologia (CONSELHO FEDERAL DE PSICOLOGIA, 2013a). $\mathrm{Na}$ organização das categorias foram agrupados os conteúdos mais pertinentes a cada uma delas. Por exemplo, na categoria Psicologia Organizacional e do Trabalho, foram incluídas respostas como: "Organizacional"; "Recursos Humanos"; "Orientação Profissional"; "Institucional".

As respostas às questões dos alunos iniciantes estão apresentadas já categorizadas na tabela abaixo (Tabela 1), com suas respectivas frequências:

Tabela 1 - Respostas dos participantes iniciantes às questões 6 e 7.

\section{Categorização das respostas dos iniciantes}

\begin{tabular}{llll}
\hline Questão 6 & F & Questão 7 & F \\
\hline Psicologia Organizacional e do Trabalho & 59 & Psicologia Organizacional e do Trabalho & 59 \\
Psicologia Clínica & 53 & Psicologia Clínica & 47 \\
Psicologia Hospitalar & 52 & Psicologia Escolar/Educacional & 41 \\
Psicologia Escolar/Educacional & 45 & Psicologia Hospitalar & 35 \\
Psicologia Jurídica & 34 & Psicologia Social & 24 \\
Psicologia Social & 21 & Psicologia Jurídica & 22
\end{tabular}


Continuação

\begin{tabular}{lclc} 
Psicologia do Esporte & 20 & Psicologia do Esporte & 14 \\
Espaços/Áreas de atuação e estudo & 12 & Psicologia de Trânsito & 8 \\
Psicologia de Trânsito & 12 & Espaços/Áreas de atuação e estudo & 7 \\
Abordagens & 10 & Abordagens & 5 \\
Pesquisa/Docência & 10 & Pesquisa/Docência & 5 \\
Instrumentos/Métodos/Técnicas & 3 & Instrumentos/Métodos/Técnicas & 2 \\
Neuropsicologia & 2 & Neuropsicologia & 2 \\
Total: & 333 & Total: & 271 \\
\hline
\end{tabular}

Fonte: Autores

As respostas dos participantes concluintes e frequências (Tabela 2): possibilitaram a formação das seguintes categorias

Tabela 2 - Respostas dos participantes concluintes às questões 6 e 7.

\begin{tabular}{lclc} 
Categorização das respostas dos concluintes & & \\
\hline Questão 6 & F & Questão 7 & F \\
\hline Psicologia Organizacional e do Trabalho & 50 & Psicologia Organizacional e do Trabalho & 40 \\
Psicologia Hospitalar & 44 & Psicologia Hospitalar & 38 \\
Psicologia Clínica & 38 & Psicologia Clínica & 36 \\
Psicologia Escolar/Educacional & 34 & Psicologia Escolar/Educacional & 33 \\
Psicologia Jurídica & 28 & Psicologia Social & 25 \\
Psicologia do Esporte & 25 & Psicologia Jurídica & 23 \\
Psicologia Social & 24 & Espaços/Áreas de atuação e estudo & 10 \\
Espaços/Áreas de atuação e estudo & 17 & Psicologia do Esporte & 9 \\
Psicologia de Trânsito & 15 & Psicologia de Trânsito & 7 \\
Pesquisa/Docência & 7 & Pesquisa/Docência & 6 \\
Plantão & 3 & Abordagens & 4 \\
Abordagens & 2 & Instrumentos/Métodos/Técnicas & 2 \\
Instrumentos/Métodos/Técnicas & & Plantão & 2 \\
Total: & 287 & Total: & 235 \\
\hline
\end{tabular}

Fonte: Autores

A área/especialidade mais citada pelos citada pelos iniciantes foi a Psicologia Clínica participantes iniciantes e concluintes, tanto como e, pelos concluintes, a Psicologia Hospitalar. O campo de atuação profissional quanto como número total de respostas emitidas pelos iniciantes disciplina oferecida por sua instituição de ensino, a essas questões (604), foi um pouco superior foi a POT. A segunda área/especialidade mais ao total de respostas dos concluintes (522). 
Sendo que o número de participantes em início de curso (61) é quase o dobro dos concluintes (38), constata-se que a média de respostas de concluintes (13,7 respostas) é bastante superior à média de respostas dos iniciantes $(9,9)$. Isso pode estar relacionado à maior quantidade de oportunidades de contato com as áreas/especialidades de Psicologia que os alunos concluintes devem ter experimentado ao longo do curso, seja pelas disciplinas cursadas e estágios realizados, seja pela exposição a textos (sob a forma de livros ou artigos científicos) lidos ao longo do processo formativo e eventos científicos dos quais possam ter participado (congressos, simpósios, jornadas, encontros etc.).

Alguns participantes demonstraram dificuldade em diferenciar as áreas/especialidades dos espaços onde o profissional de Psicologia atua; por exemplo, tivemos respostas assim formuladas: "asilos"; "locais de repouso"; "escolas"; "Centros de Atenção Psicossocial (CAPS)". Algumas respostas apontavam áreas de estudo, tais como: "Emergências e Desastres"; "Necessidades Especiais"; "Psicologia da Morte". Houve ainda, respostas apontando instrumentos, métodos e/ou técnicas psicológicas, a saber: "Recrutamento e Seleção"; "Psicodiagnóstico"; "Adestramento". Abordagens da ciência psicológica também fizeram parte das respostas dos participantes (“Análise do Comportamento", "Psicanálise" e "Fenomenologia", por exemplo), em lugar de áreas/especialidades de atuação, o que demonstra falta de clareza em parte dos respondentes quanto ao que vem a ser área/especialidade de atuação em Psicologia e, portanto, uma provável falha formativa, ou seja, uma fragilidade no processo ensino-aprendizagem, motivado por um provável déficit na qualidade do ensino ofertado pelas instituições ou pela, igualmente provável, dificuldade na aprendizagem por parte do estudante de Psicologia participante da pesquisa, posto que "área/especialidade" de atuação foi tomada por "espaço de trabalho", assim como referenciais teórico-metodológicos foram tomados como "áreas de atuação".
A questão 8 foi enunciada da seguinte forma: "Que coisas você já ouviu falar ou estudou sobre Psicologia Organizacional e do Trabalho"? $\mathrm{Na}$ análise do conteúdo coletado foram obtidas três categorias. Foram privilegiadas as ideias, lembranças, que os participantes tiveram em razão do que estudaram ou ouviram falar e não a classificação de acordo com os referenciais mais atuais da POT.

As ideias expressas pelos participantes da pesquisa foram agrupadas nas seguintes subcategorias: "Opiniões positivas"; "Opiniões negativas" e "Opiniões neutras", sendo que por opiniões positivas entendemos aquelas respostas dos participantes da pesquisa que representam a POT como uma área/especialidade da Psicologia que objetiva e possui potencial para atuar em prol da saúde do trabalhador, promovendo o bem-estar e o prazer nos contextos de trabalho e que, portanto, está alinhada com a visão não fragmentada da POT, aquela visão apresentada por nós no texto de introdução e que encontra fundamento nas formulações do CFP, da SBPOT e de Zanelli, Bastos e Rodrigues (2014), por exemplo. Ao contrário, as respostas categorizadas como opiniões negativas, são aquelas que se identificam com esta visão dicotomizada da POT, ou seja, que ainda diferencia a Psicologia Organizacional da Psicologia do Trabalho, e que mais se aproxima da versão Psicologia da Indústria, enquanto modelo não superado de formação e atuação do Psicólogo nos contextos organizacionais de trabalho. $\mathrm{Na}$ categoria de opiniões neutras estão aquelas respostas que percebemos como desprovidas de uma posição (entre a visão positiva e negativa, aqui consideradas) e de uma crítica sobre a POT ou seu protagonismo nos contextos organizacionais de trabalho e sociedade.

As frequências nas três subcategorias, para iniciantes e concluintes, foram as seguintes (Gráfico 1): 
Gráfico 1 - Categorias de respostas de iniciantes e concluintes à Questão 8.

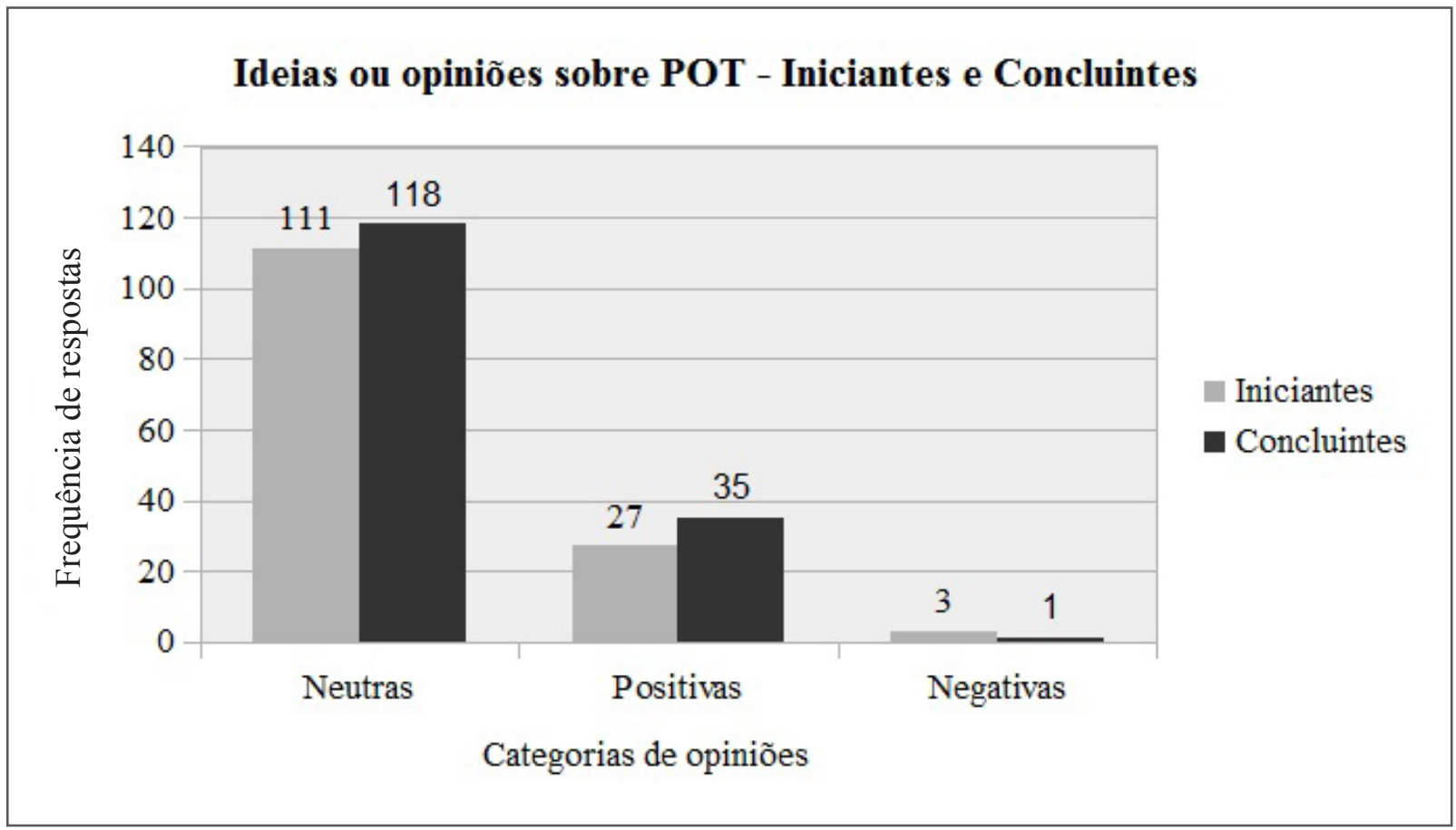

Fonte: Autores

Apenas um dos participantes não única resposta classificada como negativa, foi respondeu a esta questão. Em geral, as ideias e opiniões negativas foram poucas. Entre os iniciantes, foram registradas apenas três respostas que expressavam opiniões negativas sobre a POT, como por exemplo: "Apenas favorece a empresa e o capitalismo". Entre os iniciantes, a semelhante: "Trabalha a favor do capital".

No Gráfico 2, são apresentadas as subcategorias de respostas dos iniciantes que consideramos neutras (111), ou seja, seus autores não se posicionaram indicando opinião passível de ser qualificada como positiva ou negativa.

Gráfico 2 - Subcategorias de respostas neutras de iniciantes à Questão 8.

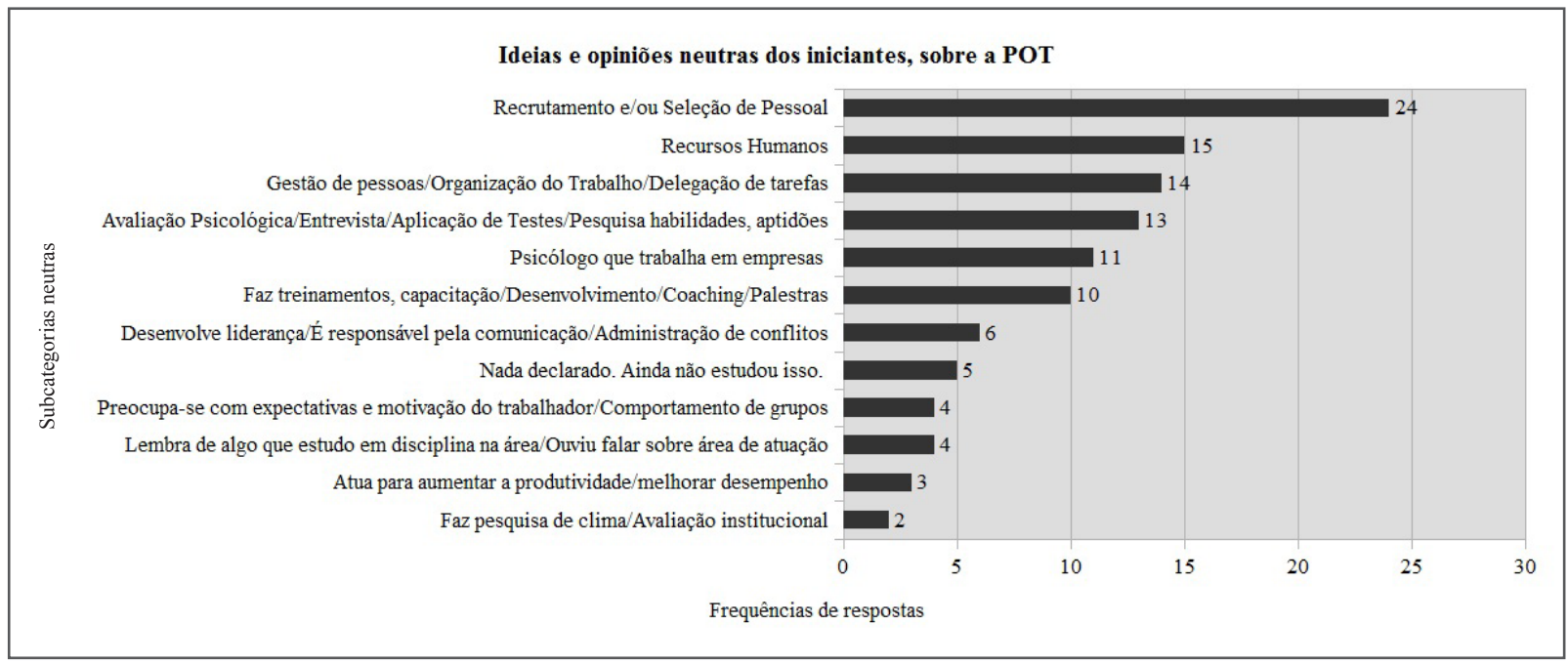

Fonte: Autores 
Como exemplo da subcategoria "Atua para aumentar a produtividade/melhorar desempenho", tem-se as respostas: "Pode também atuar quando um departamento tem algum rendimento mais baixo do que o normal" e "O psicólogo organizacional atua em empresas, promovendo o bem-estar dos colaboradores para se obter o seu melhor rendimento". A subcategoria "Psicólogo que trabalha em empresas" tem as seguintes respostas como exemplos: "Trabalha em empresas de pequeno, médio e grande porte"; "Trabalha em empresas, como indústrias"; "Trabalha no RH, em empresas grandes". Como exemplo da subcategoria "Gestão de pessoas/Organização do Trabalho/ Delegação de tarefas” tem-se as respostas: “Atua nas práticas organizacionais"; "Sobre a organização do ambiente, gestão, quadro de funcionários e pessoal”; "Sobre a organização do ambiente, gestão, quadro de funcionários"; "Envolve a área de recursos humanos de uma empresa, parte de organização de pessoal, convivência dos colaboradores".

Entre os concluintes, 118 respostas tiveram seu conteúdo classificado como neutro. Este grupo era composto de apenas 38 participantes, o que implica numa média de 3,10 respostas por concluintes, enquanto os iniciantes apresentaram, em média, 1,81 resposta. As respostas neutras dos concluintes foram agrupadas nas seguintes subcategorias, com suas respectivas frequências (Gráfico 3):

Gráfico 3 - Subcategorias de respostas neutras de concluintes à Questão 8.

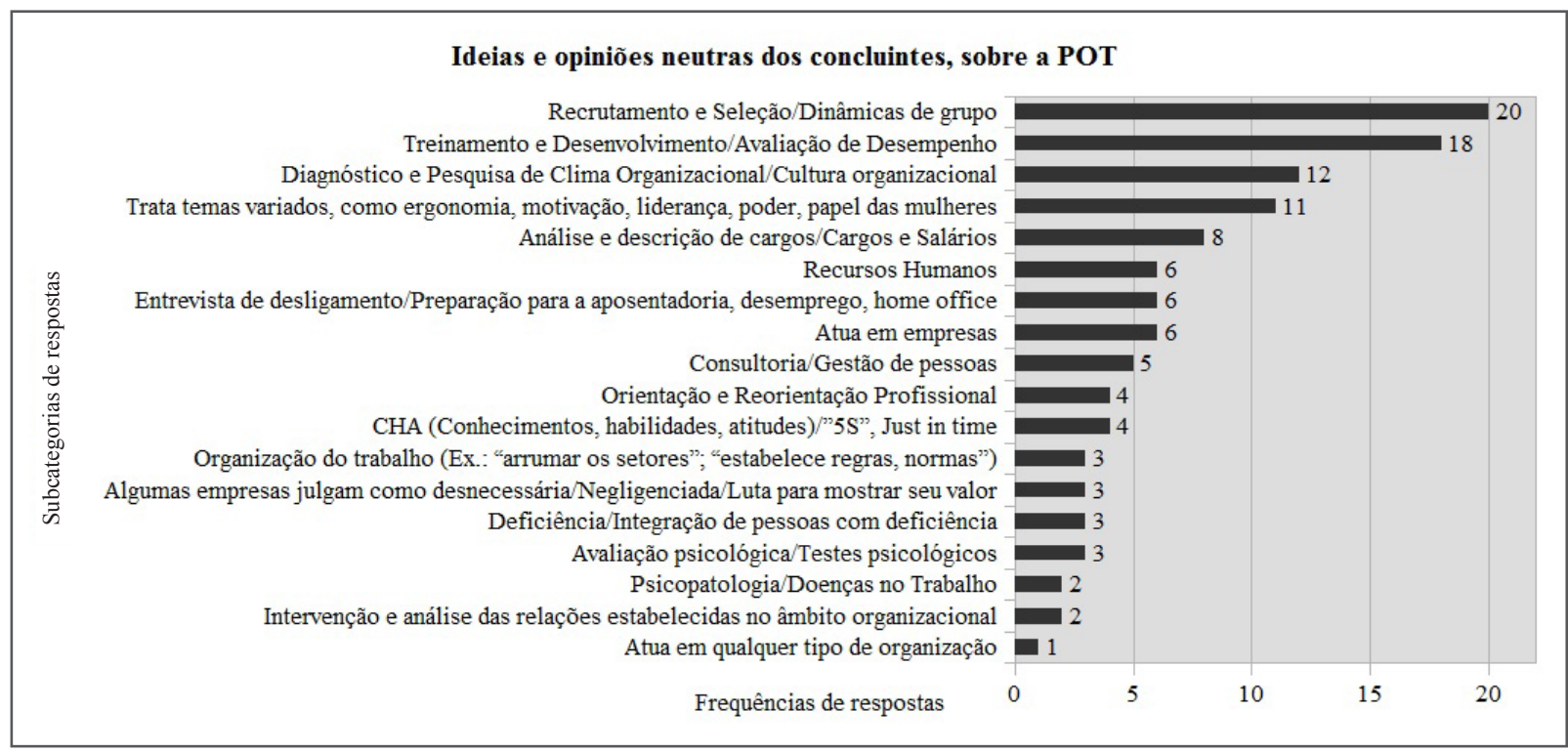

Fonte: Autores

As opiniões positivas emitidas pelos seguintes subcategorias e suas respectivas participantes iniciantes foram agrupadas nas frequências (Gráfico 4 [próxima página]). 
Gráfico 4 - Subcategorias de respostas positivas de iniciantes à Questão 8.

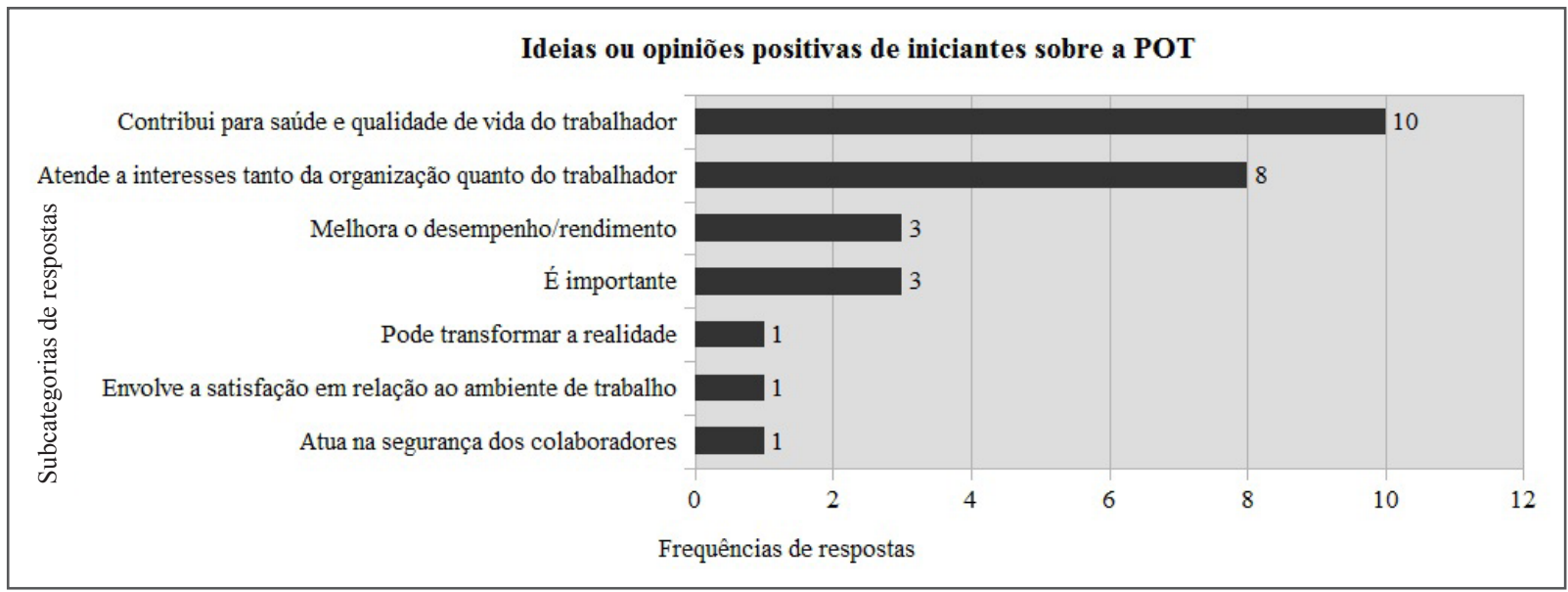

Fonte: Autores

As respostas foram agrupadas de acordo com seu conteúdo e, portanto, foi necessária a construção de subcategorias diferentes para participantes iniciantes e concluintes. Algumas respostas dos concluintes, classificadas como "positivas", foram assim expressas: "Contribui para a qualidade de vida do trabalhador"; "Deve conciliar o interesse do trabalhador e da empresa, procurando o melhor para ambos"; "É uma área em que se ganha muito bem". As subcategorias construídas, com suas respectivas frequências são as que se seguem (Gráfico 5).

Gráfico 5 - Subcategorias de respostas positivas de concluintes à Questão 8.

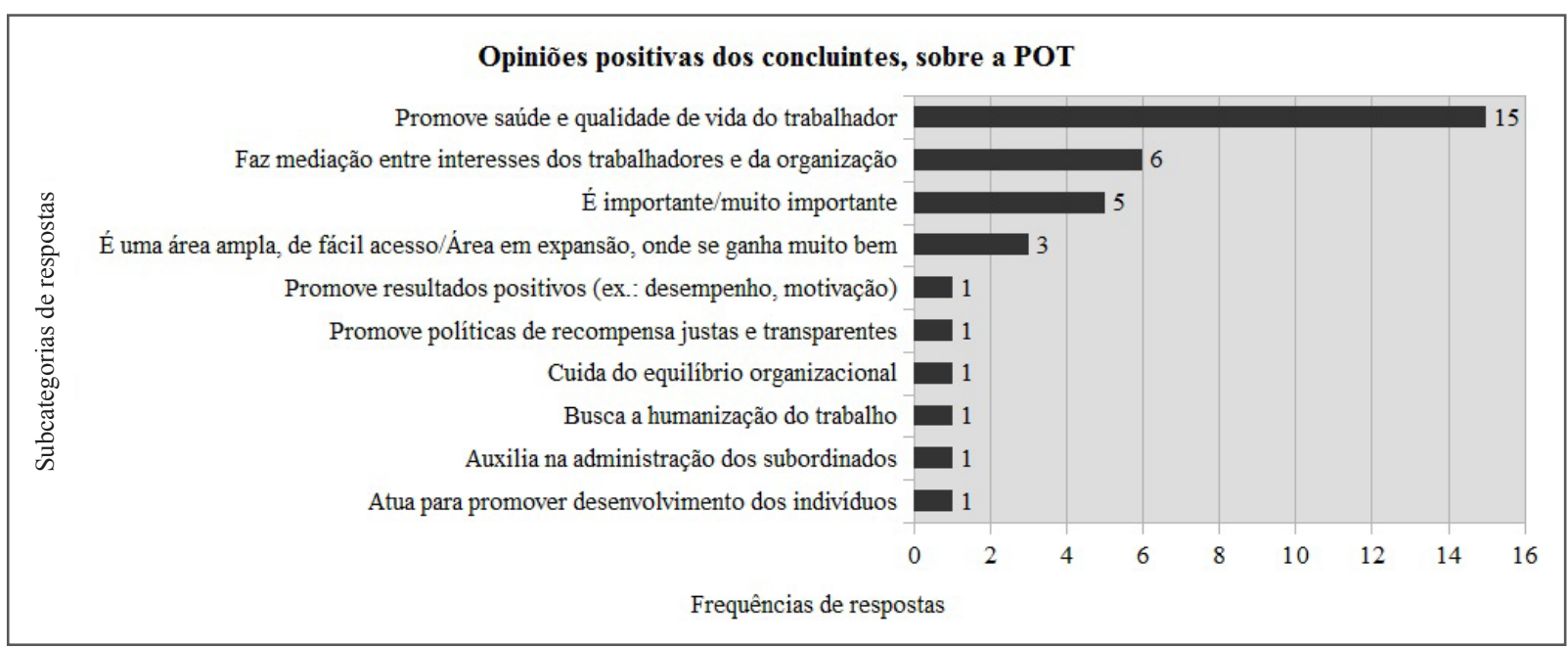

Fonte: Autores

Fica evidente que, na percepção de vários participantes, a POT atua em caráter precipuamente instrumental, servindo aos interesses das organizações. Até alguns dos que responderam que ela "promove a saúde do trabalhador" nos contextos organizacionais, apontaram para o fato de que a finalidade última desta promoção de saúde seria a melhoria do desempenho individual e coletivo, o que se traduz, na prática, por aumento da produtividade e lucratividade para a organização. Tal percepção também é encontrada na literatura (ZANELLI, 2002) e já houve manifestação sobre 
tal tema até por parte da Associação Brasileira de Psicologia Organizacional e do Trabalho (SBPOT), que, em seu documento intitulado "Manifesto da Associação Brasileira de Psicologia Organizacional e do Trabalho (SBPOT) Psicologia do trabalho e das organizações: não atuamos pela cisão", assim se posicionou:

[...] Deparamo-nos hoje, novamente, com a difusão de um discurso promotor daquela cisão, veiculado por pessoas ligadas direta ou indiretamente a grupos detentores de recursos políticos e financeiros, que criaram bases de poder duradouras em algumas instâncias institucionalizadas de interlocução da psicologia brasileira. Tal discurso é de que só será possível uma psicologia do trabalho plenamente comprometida com os interesses do trabalhador, se houver uma cisão com uma psicologia das organizações, que estaria supostamente comprometida com os interesses do capital e contra os trabalhadores (ASSOCIAÇÃO BRASILEIRA DE PSICOLOGIA ORGANIZACIONAL E DO TRABALHO, 2009, p. 1).

Outro aspecto a se notar é o de que há respostas dos participantes da pesquisa apontando ser função da POT organizar o trabalho em termos de ambiente ou de tarefa, função que entendemos muito mais compatível com o rol daquelas atribuídas ao Administrador de Empresas e, por vezes até, ao Engenheiro de Produção, quando projetam e definem formas de organizar as diferentes etapas dos processos produtivos. Cabe, portanto aqui, definir o que é de fato a atribuição do Psicólogo nos contextos organizacionais de trabalho, e, para tanto, trazemos as contribuições de Zanelli e Bastos (2014, p. 490):

[...] movimentos estão reconfigurando a prática profissional do psicólogo organizacional e do trabalho no Brasil. O primeiro deles ocorre no interior das práticas tradicionais e que constituem o núcleo central da representação do que significa ser psicólogo organizacional, influenciadas pelo desenvolvimento científico e pelas transformações nos contextos de trabalho. $\mathrm{O}$ segundo movimento inovador caracteriza-se como um alargamento do cargo, ou seja, a inserção do psicólogo em equipes multidisciplinares de recursos humanos conduziu a que novas atividades, até então desempenhadas por outros profissionais, também fossem incorporadas ao leque de competências do psicólogo. $\mathrm{O}$ terceiro movimento destaca transições que estão configurando uma intervenção do psicólogo em âmbitos mais complexos da própria organização.

Entre os iniciantes, é compreensível a existência de algumas respostas a esta questão como "não sei", "não estudei ainda" ou até mesmo "não tenho noção", como de fato registramos. Ainda assim, vários participantes deste grupo conseguiram apontar algo que estudaram ou ouviram falar relacionado à POT. A resposta mais frequente, neste caso, foi mencionar a atividade de recrutamento e seleção de pessoal $(\mathrm{f}=24)$. Entre os concluintes, a ideia mais recorrente acerca da POT também foi de que ela tem o papel de atuar na seleção e contração de pessoal $(\mathrm{f}=20)$.

Este padrão ou intensidade de respostas entre nossos sujeitos, corrobora nossa percepção de que ainda recai sobre a POT um estigma que se relaciona com seu processo histórico de desenvolvimento, haja vista o fato de que a então Psicologia da Indústria caracterizava-se por uma forte atuação em processos de recrutamento e seleção de pessoal (ZANELLI; BORGESANDRADE; BASTOS, 2004).

Tanto estudantes de Psicologia quanto representantes de organizações de trabalho (trabalhadores comuns e gestores), ainda vinculam a atividade do Psicólogo Organizacional e do Trabalho às práticas de recrutamento e seleção de pessoal - quando não, de treinamento de pessoal - modo pelo qual de fato a Psicologia começou a atuar nos contextos organizacionais de trabalho (ZANELLI;BASTOS; RODRIGUES, 2014). O fato é que, de sua gênese até o momento atual, esta área da Psicologia passou por inúmeras transformações e ao longo desse processo foi diversificando em muito a sua atuação (BASTOS; GALVÃOMARTINS, 1990). Assim, essa resposta de nossos sujeitos não nos é estranha, principalmente entre 
os iniciantes, e a lemos como o reflexo de uma realidade que ainda não foi superada.

Uma de nossas hipóteses em relação a este tema residia na possibilidade de um achado que não conseguimos realizar por meio desta pesquisa e com estes sujeitos, a saber: a de que entre estudantes iniciantes e concluintes haveria uma diferença significativa em termos de qualidade de resposta, profundidade, além de relevantes variações na citação dos fazeres do Psicólogo Organizacional e do Trabalho, ultrapassando essa quase "cristalizada vocação" para o Recrutamento e Seleção que a história nos conferiu. O documento intitulado, "Atribuições Profissionais do Psicólogo no Brasil", de autoria do CFP, já em 1992, dissertava sobre vinte (20) diferentes itens de "Descrição de Ocupação (detalhamento das atribuições)" do Psicólogo nos contextos de trabalho, os quais não podemos aqui citar, mas recomendamos leitura (CONSELHO FEDERAL DE PSICOLOGIA, 1992).

A ausência ou a não predominância de respostas entre nossos sujeitos, convergentes com estes fazeres e atribuições apresentadas e reconhecidas pelo CFP, remete-nos a uma indagação sobre a qualidade da formação que os mesmos têm recebido, posto que se mantém uma representação da POT identificada com as práticas marcantes de suas origens e um paralelo desconhecimento de fazeres que vão além daqueles primeiros. Nossa indagação, pode assim ser expressa, portanto: a formação em POT recebida por nossos participantes está reforçando essa representação limitada e/ou então, não contribuindo para sua desconstrução, ressignificação e avanço?; e, nesse sentido, estamos identificando um processo de formação de psicólogos que mais "deforma" do que melhor forma, ou seja, um processo que contribui pouco para a construção de uma identidade da POT e do psicólogo nela atuante, próxima do que se preconiza na atualidade, em especial pelos pesquisadores e entidades aqui já citadas?

Diante da questão 10 - "O que o Psicólogo Organizacional e do Trabalho faz?" - os participantes apresentaram as seguintes respostas, aqui categorizadas:
Iniciantes: cuida do trabalhador (propicia melhorias na saúde dos trabalhadores; recebe trabalhadores com problemas de desempenho ou de saúde para ajudá-los; faz os encaminhamentos dos trabalhadores a outros profissionais e instituições quando necessário; atua individual ou coletivamente no contexto de trabalho, buscando otimizar o trabalho em paralelo à saúde emocional do trabalhador; zela pela saúde mental dos trabalhadores); atua em todos os subsistemas RH/GP, desde a contratação até a demissão do trabalhador (recruta pessoal; atua em seleção de pessoal; avalia perfis de pessoas candidatas ao emprego; faz entrevistas de seleção; realiza avaliação psicológica; aplica testes para selecionar pessoas; realiza entrevistas de desligamento; demite trabalhadores); faz a "ponte" entre trabalhadores e organização (ajuda na relação entre funcionários e empresas; elabora estratégias visando o crescimento profissional dos trabalhadores e da organização); avalia níveis de satisfação dos trabalhadores; ministra palestras motivacionais; atua na realização de análises da instituição; procura melhorar o ambiente de trabalho (trabalha pela boa convivência entre os funcionários); e atua em treinamentos (desenvolve pessoas; realiza ações de acompanhamento e orientação como o coaching).

Concluintes: estuda e intervém nas relações de trabalho e nas relações interpessoais estabelecidas na organização (realiza processos de diagnósticos organizacionais visando identificar problemas e propor soluções; promove ações com o objetivo de trazer melhorias ao ambiente de trabalho, à cultura organizacional e à qualidade de vida dos trabalhadores; busca humanizar as relações de trabalho nas organizações, de maneira a conseguir o sucesso organizacional e a promoção da saúde do trabalhador); atua no recrutamento e seleção de pessoal (realiza tanto o recrutamento externo quanto interno, bem como a seleção de pessoas; planeja e realiza seleção de pessoas baseada em competências; atua na integração de novos trabalhadores; acompanha os trabalhadores em processos de mudanças de cargo 
e desligamentos; realiza avaliação psicológica; atua no desenvolvimento e avaliação de perfis); atua em todos os subsistemas do RH (atua sobre as demandas da organização nas práticas que envolvem os recursos humanos; desenvolve os programas de GP nas organizações; atua junto aos interesses dos trabalhadores e das organizações, facilitando a comunicação, contribuindo para um ambiente mais harmônico e auxiliando na resolução de conflitos); realiza ações de treinamento e desenvolvimento dos trabalhadores (treinamento e desenvolvimento de equipes; realiza palestras; realiza orientação em processos de desenvolvimento profissional e de carreira); participa da definição, elaboração e realização de projetos relacionados à responsabilidade social das organizações; realiza atendimentos individuais e em grupo nos contextos organizacionais; estuda o "fator humano" nas organizações (atua em prol à manutenção da motivação dos trabalhadores; desenvolve programas de avaliação de desempenho, reconhecimento e recompensa dos trabalhadores); é responsável pelo processo de descrição e análise de cargos; auxilia na estruturação do plano de cargos e salários das organizações; e presta consultorias internas e externas à organização de trabalho.

Consideramos importante registrar que dentre os participantes da pesquisa, 10 estudantes iniciantes (eram 61), deixaram essa pergunta sem resposta ou a responderam informando sobre a ausência de conhecimento em relação ao tema. Entre os estudantes concluintes (eram 38) não houve resposta em branco ou apontamento de impossibilidade de responder. Tal fato, para além da qualidade das respostas obtidas, indica que os concluintes possuem conhecimentos passíveis de serem considerados como mais amplos e diversificados em comparação aos apresentados pelos participantes iniciantes, contudo, e pela perceptível repetição temática, associada à pequena variação/apresentação de novos itens de resposta, verifica-se que a diferença não se apresenta expressiva, ou seja, parece representar sim a existência de um avanço e aprimoramento na aprendizagem, mas qualitativamente questionável se consideramos a diversidade dos fazeres e potencial de participação dos Psicólogos Organizacionais e do Trabalho em seus contextos de inserção (BASTOS; GOMIDE, 2010; BASTOS; YAMAMOTO; RODRIGUES, 2013; CAMARGO; GOULART JUNIOR; LEITE, 2017; CONSELHO FEDERAL DE PSICOLOGIA, 1992; YAMAMOTO; FALCÃO; SEIXAS, 2011; ZANELLI, 2002; ZANELLI; BORGESANDRADE; BASTOS, 2004).

\section{Considerações Finais}

A hipótese que motivou o desenvolvimento desta pesquisa foi a de que haveria diferença qualitativa entre as respostas emitidas por participantes iniciantes e concluintes, e que tal diferença seria decorrente da exposição dos mesmos aos conteúdos e experiências proporcionados pelo Curso de Formação do Psicólogo. Assim, esperávamos certo desenvolvimento ou maturidade teórico-conceitual decorrentes da aprendizagem que poderiam ser constatadas mediante a percepção de: um maior repertório léxico sobre a área e um maior repertório de práticas relacionadas à POT; uma maior criticidade de posicionamento acerca da história, contexto atual e desafios da POT no Brasil; uma visão mais atual da POT, mais desconectada de seu modelo original, ou seja, de uma Psicologia da Indústria ou daquela paradigmática separação entre Psicologia do Trabalho e Psicologia Organizacional; um mais profundo conhecimento sobre aspectos relativos ao compromisso da POT com a qualidade de vida no trabalho, saúde do trabalhador e desenvolvimento das organizações; e uma superação da visão do Psicólogo Organizacional e do Trabalho enquanto profissional de $\mathrm{RH}$, atuante de forma concentrada em práticas de recrutamento e seleção de pessoal ou em treinamentos.

Esta hipótese, contudo, não foi confirmada, uma vez que houve pouca diferença qualitativa ou em relação à profundidade das respostas ou em relação à variabilidade de conteúdo, o que nos leva a inevitável conclusão de que o 
momento atual da formação de nossos Psicólogos Organizacionais e do Trabalho, na cidade e região pesquisada, carece de uma atenção especial para que, uma vez analisado, revisto e transformado, possa contribuir mais efetivamente com a constituição de profissionais mais bem formados do ponto de vista teórico-metodológico e que venham, consequentemente, atuar de forma mais consistente, comprometida e crítica.

A diferença mais significativa percebida entre os dois grupos foi em relação à quantidade de respostas, sendo que os concluintes apresentaram maior quantidade de respostas e os iniciantes se omitiram mais. Devemos pontuar que a diferença de quantidade de respostas não necessariamente indica, mediante ao conjunto de dados coletados, que há um significativo enriquecimento léxicoconceitual por parte dos estudantes concluintes em relação aos iniciantes. A variação de conteúdo entre as respostas de iniciantes e concluintes foi pouco significativa, ou seja, tivemos menos estudantes iniciantes falando dos diferentes temas relativos à POT e sobre os fazeres do profissional a ela vinculado, mas as muitas respostas expressas pelos participantes concluintes não se diferenciaram das respostas dos iniciantes, ou seja, não foram mais ricas, profundas, críticas, nem tampouco mais diversas. Na verdade, e esta é mais uma de nossas conclusões sobre este estudo, notamos que ainda se encontra com mais força de presença para os estudantes de Psicologia (iniciantes e concluintes) participantes de nossa pesquisa, a imagem do Psicólogo Industrial, tanto quanto a imagem de uma POT que serve mais aos interesses do capital do que aos interesses dos trabalhadores e da sociedade como um todo, o que nos permite inferir que o ensino da POT e do compromisso social da Psicologia (BOCK et al., 2007), pelo menos nos cursos pesquisados, pode estar ocorrendo de forma fragmentada, desconectada, ou seja, um ensino mais focado em seus procedimentos técnicos e com implicações sobre o desempenho dos trabalhadores e, portanto no aprimoramento da produtividade organizacional com vistas ao ganho desta no mercado, do que com foco nos projetos de avaliação e intervenção que, por sua vez, poderiam implicar na promoção de qualidade de vida no trabalho e no seu consequente impacto positivo sobre a saúde do trabalhador.

Ainda, e como também constatado em outras pesquisas anteriormente citadas, a Psicologia parece ser uma ciência e profissão marcada fortemente pela presença das mulheres; isso observamos empiricamente nos cursos de Psicologia aos quais tivemos acesso (78 mulheres e 21 de homens, entre os 99 participantes da pesquisa). Outro aspecto importante e que convém ser mencionado aqui é que, também refletindo uma realidade nacional, nossos participantes se aproximaram da Psicologia e pretendem atuar nela, muito mais motivados pela área clínica do que pela atuação em POT; fenômeno que consideramos tão interessante quanto pertinente em termos de análise do contexto, sobretudo se nos atermos ao fato de que as mulheres ocupam de forma predominante profissões que envolvem o cuidado e que, muito provavelmente, seja a atuação em Psicologia Clínica a mais forte expressão desse cuidado no exercício profissional da Psicologia. Contudo, vale observar que o cuidado também se presentifica nas práticas da POT, como por exemplo: no atendimento, na maioria das vezes realizado em modalidade individual, das demandas emocionais de trabalhadores, oriundos da sua relação com o trabalho, com as pessoas e com a organização; nas entrevistas de seleção e de desligamento, onde a escuta qualificada se apresenta tanto como estratégia de coleta de dados quanto forma de acolhimento; na avaliação psicológica; nos processos de readaptação profissional, se trabalhadores com deficiência ou retornando de licenças/afastamentos por problemas de saúde; na atenção aos agravos à saúde física e mental dos trabalhadores; no aconselhamento e orientação profissional e de carreira; entre outras formas de cuidado, tanto aqueles voltados aos trabalhadores quanto aqueles que tomam como alvo, a própria organização/ instituição (projetos de responsabilidade social; cultura e clima organizacional etc.). 
Para além desta característica, verificamos que há uma relação desigual entre os períodos de oferecimento dos cursos de graduação em Psicologia na cidade pesquisada, sendo cinco oferecidos no período noturno e apenas um no período integral. Associado a este fato, está também a questão do caráter público ou privado de acesso e frequência aos cursos, posto que, como vimos, das cinco instituições de ensino atuantes na formação do Psicólogo, quatro são privadas e apenas uma é pública.

E o que estas duas últimas características significam? Que a maioria dos estudantes de Psicologia participantes de nossa pesquisa se dedicam à sua formação em regime de tempo parcial, conciliando o estudo com o trabalho ou outras atividades e, desta forma, podendo se dedicar menos às oportunidades de formação que ocorrem fora dos muros da instituição de ensino, a exemplo dos projetos de extensão universitária, das pesquisas de iniciação científica, da participação em eventos culturais e científicos e dos estágios extracurriculares.

Consideramos adequado finalizar nossas reflexões com a propositura de estratégias que vislumbramos como alternativas possíveis de serem construídas e postas em prática com a finalidade de contribuir para um melhor desenvolvimento do ensino da POT em nossa região bem como noutras do Brasil. A exemplo do que têm feito outras instituições de ensino superior que promovem cursos de Formação do Psicólogo, poderiam se reunir docentes e estudantes de Psicologia interessados e comprometidos com a POT para discutir, planejar e executar projetos como: a) cada curso, a seu tempo e dentro de suas condições, incorporar a seus projetos pedagógicos, práticas de ensino interdisciplinares e conteúdos transversais que tornem possível a discussão sobre o trabalho mais presente no currículo, e de forma crítica; como na disciplina de Ética Profissional, por exemplo, onde por meio do estudo dos princípios fundamentais do nosso Código de Ética, a POT pode ser apresentada como potencial ferramenta ou estratégia dos Psicólogos no enfrentamento das desigualdades, das injustiças, do não respeito aos direitos humanos e dos riscos à saúde dos trabalhadores que muitos contextos organizacionais imputam aos mesmos; b) realização de fóruns de discussão sobre o currículo da Psicologia nos cursos (em funcionamento na cidade, na região, no estado), de forma a buscar avaliar e compreender, qual Psicologia está sendo ensinada e de que Psicologia precisamos, para que a formação esteja cada vez mais alinhada às reais demandas e desafios que o contexto apresenta; c) a criação de grupos intra e interinstitucionais de estudos e pesquisas em POT; d) dar visibilidade e incentivar a continuidade de eventos científicos como o Congresso de Psicologia Organizacional e do Trabalho do Centro-Oeste Paulista (CPOT), que ocorre a cada dois anos e tem congregado participantes de várias localidades brasileiras; e) fundação de um laboratório de POT com caráter interinstitucional, ou seja, sediado numa das instituições de ensino, mas com a participação de todas as outras possibilitando sua exequibilidade; f) maior investimento e apoio às empresas juniores de Psicologia, as quais contribuem significativamente para o desenvolvimento da identidade profissional e afinidade dos estudantes com a área da POT; g) fundação de uma revista que concentre trabalhos resultantes de estudos e pesquisas sobre POT realizados por pesquisadores da área; h) um futuro curso de pós-graduação, em níveis de lato sensu e, posteriormente, de stricto sensu na área da POT, para tornar ainda mais consolidada a presença da POT por meio de profissionais com formação sólida e especializada.

\section{Referências}

ASSOCIAÇÃO BRASILEIRA DE PSICOLOGIA ORGANIZACIONAL E DO TRABALHO SBPOT. Manifesto da Associação Brasileira de Psicologia Organizacional edo Trabalho(SBPOT): psicologia do trabalho e das organizações: não atuamos pela cisão. Brasília, SBPOT, 2009. Disponível em: https://bit.ly/3fUQrOW. Acesso em: 10 set. 2018.

BARDIN, L. Análise de conteúdo. Lisboa: Edições 70, 2011. 
BASTOS, A. V. B.; GALVÃO-MARTINS, A. H. C. O que pode fazer o psicólogo organizacional. Psicologia: ciência e profissão, Brasília, v. 10, n. 1, p. 10-18, 1990. Disponível em: https://bit. ly/2AspAtk. Acesso em: 14 set. 2018.

BASTOS, A. V. B.; GOMIDE, P. I. C. O psicólogo brasileiro: sua atuação e formação profissional. In: YAMAMOTO, O. H.; COSTA, A. L. F. (org.). Escritos sobre a profissão de psicólogo no Brasil. Natal: EDUFRN, 2010. p. 229-255.

BASTOS, A. V. B.; YAMAMOTO, O. H.; RODRIGUES, A. C. A. Compromisso social e ético: desafios para a atuação da psicologia organizacional e do trabalho. In: BORGES, L. O.; MOURÃO, L. (org.). O trabalho e as organizações: atuações a partir da Psicologia. Porto Alegre: Artmed, 2013. p. 25-52.

BOCK, A. M. B.; FERREIRA, M. R.; GONÇALVES, M. G. M.; FURTADO, O. Sílvia Lane e o projeto do "Compromisso Social da Psicologia". Psicologia \& Sociedade, Porto Alegre, v. 19, n. 2, p. 46-56, 2007. Disponível em: https:// bit.ly/2X8Ncv0. Acesso em: 12 mar. 2018.

BRASIL. Ministério da Saúde. Resolução n. 466, de 12 de dezembro de 2012. Aprova as diretrizes e normas regulamentadoras de pesquisas envolvendo seres humanos. Brasília: Ministério da Saúde, 2012. Disponível em: https://bit.ly/2X2j179. Acesso em: 14 set. 2018.

CÂMARA, R. H. Análise de conteúdo: da teoria à prática em pesquisas sociais aplicadas às organizações. Gerais: Revista Interinstitucional de Psicologia, São João Del-Rei, v. 6, n. 2, p. 166178, 2013. Disponível em: https://bit.ly/3dPTOEZ. Acesso em: 14 set. 2018.

CAMARGO, M. L.; GOULART JÚNIOR, E.; LEITE, L. P. O psicólogo e a inclusão de pessoas com deficiência no trabalho. Psicologia: ciência e profissão, Brasília, v. 37, n. 3, p. 799-814, set. 2017. Disponível em: https://bit.ly/3fXWIcE. Acesso em: 14 set. 2018.

CHIAVENATO, I. Recursos humanos: o capital humano das organizações. 9. ed. São Paulo: Atlas, 2009.
CONSELHO FEDERAL DE PSICOLOGIA. A psicologia brasileira apresentada em números. Brasília: CFP, 2017. Disponível em: https://bit. ly/2TbwaLr. Acesso em: 14 set. 2018.

CONSELHO FEDERAL DE PSICOLOGIA. Atribuições profissionais do psicólogo no Brasil: contribuição do Conselho Federal de Psicologia ao Ministério do Trabalho para integrar o catálogo brasileiro de ocupações. Brasília: CFP, 1992. Disponível em: https://bit.ly/2z5Guh3. Acesso em: 14 set. 2018.

CONSELHO FEDERAL DE PSICOLOGIA. Quem é o psicólogo brasileiro? São Paulo: Edicon; Curitiba: EDUC, 1988.

CONSELHO FEDERAL DE PSICOLOGIA. Resolução CFPn. 013/2007: institui a Consolidação das Resoluções relativas ao Título Profissional de Especialista em Psicologia e dispõe sobre normas e procedimentos para seu registro. Brasília: CFP, 2013a. Disponível em: https://bit.ly/3fVDqEZ. Acesso em: 14 set. 2018.

CONSELHO FEDERAL DE PSICOLOGIA. Uma profissão de muitas e diferentes mulheres. Brasília: CFP, 2013b. Disponível em: https://bit. ly/3bAQGv9. Acesso em: 14 set. 2018.

GONZÁles REY, F. L. Pesquisa qualitativa em Psicologia: caminhos e desafios. São Paulo: Cengage Learning, 2005.

INSTITUTO BRASILEIRO DE OPINIÃO PÚBLICA E ESTATÍSTICA. Pesquisa de opinião com psicólogos inscritos no Conselho Federal de Psicologia. Brasília: CFP, 2004. Disponível em: https://bit.ly/2Auiwwk. Acesso em: 14 set. 2018.

IVANCEVICH, J. M. Gestão de recursos humanos. 10. ed. São Paulo: McGraw-Hill, 2008.

MARRAS, J. P. Administração de recursos humanos: do operacional ao estratégico. 15. ed. São Paulo: Saraiva, 2006.

MINAYO, M. C. S. (org.). Pesquisa social: teoria, método e criatividade. 21. ed. Petrópolis: Vozes, 2016.

SPECTOR, P. E. Psicologia nas organizações. 4. ed. São Paulo: Saraiva, 2012. 
YAMAMOTO, O. H.; FALCÃO, J. T. R.; SEIXAS, P. S. Quem é o estudante de psicologia do Brasil? Avaliação Psicológica, Itatiba, v. 10, n. 3, p. 209232, 2011. Disponível em: https://bit.ly/362SnAC. Acesso em: 14 set. 2018.

ZANELLI, J. C. O psicólogo nas organizações de trabalho. Porto Alegre: Artmed, 2002.

ZANELLI, J. C.; BASTOS, A. V. B. Inserção profissional do psicólogo em organizações e no trabalho. In: ZANELLI, J. C.; BORGESANDRADE, J. E.; BASTOS, A. V. B. (org.). Psicologia, organizações e trabalho no Brasil. 2. ed. Porto Alegre: Artmed, 2014. p. 466-491.

ZANELLI, J.C.; BASTOS,A. V.B.; RODRIGUES, A. C. A. Campo profissional do psicólogo em organizações e no trabalho. In: ZANELLI, J. C.; BORGES-ANDRADE, J. E.; BASTOS, A. V. B. (org.). Psicologia, organizações e trabalho no Brasil. 2. ed. Porto Alegre: Artmed, 2014. p. 449582.

ZANELLI, J. C.; BORGES-ANDRADE, J. E.; BASTOS, A. V. B. (org.). Psicologia, organizações e trabalho no Brasil. Porto Alegre: Artmed, 2004.

ZANELLI, J. C.; BORGES-ANDRADE, J. E.; BASTOS, A. V. B. (org.). Psicologia, organizações e trabalho no Brasil. 2. ed. Porto Alegre: Artmed, 2014. 